\title{
Catch-and-Release Mortality of Spotted Seatrout in Texas
}

\author{
Gregory W. Stunz* and David A. McKee \\ Department of Life Sciences, Texas A\&M University-Corpus Christi, \\ 6300 Ocean Drive, Corpus Christi, Texas 78412, USA
}

\begin{abstract}
Catch and release is becoming more common as a management tool in marine recreational fisheries. Clearly, a critical factor in determining different management scenarios that use this strategy is postcapture survival. We investigated the mortality associated with catch and release in the fishery for spotted seatrout Cynoscion nebulosus in south Texas. Specifically, this study investigated the mortality for hook-andline-captured spotted seatrout as a function of bait type, hook type, angler skill level, and fish size. Using a variety of angling techniques, we captured 448 spotted seatrout ranging from 250 to $760 \mathrm{~mm}$ total length (TL) and assessed mortality in replicate field enclosures. The overall short-term mortality for all treatments was relatively low (11\%); the majority of fish survived. The exception was angler skill level. Angling by novices produced a significantly higher mortality rate than angling by skilled anglers; however, mortality averaged only $18 \%$ even for inexperienced anglers. To evaluate long-term mortality, we monitored 27 spotted seatrout held in a laboratory facility for $30 \mathrm{~d}$; the fish showed no signs of long-term mortality. We observed $11 \%$ mortality during the first $48 \mathrm{~h}$ and no mortality during the subsequent $28 \mathrm{~d}$. In an attempt to increase the abundance of "trophy" ( $>635 \mathrm{~mm}$ TL) spotted seatrout, Texas has adopted new slot limit regulations that allow only one trophy-size fish to be kept per person per day. We targeted larger (635-736 mm TL) fish to assess the mortality associated with this size-group. Regression analysis showed no size-related mortality. The location of hook-related injuries may be the most important factor in determining catch-and-release mortality. Anatomical hooking location was not a factor in the analyses but was treated as a component of experimental treatment level; however, we observed that mortality was typically associated with hooking location rather than angling method or bait type. These data suggest that management options involving the release of spotted seatrout, including those larger than $635 \mathrm{~mm}$ TL, are viable tools.
\end{abstract}

Growing competition in our marine fishery resources has led fisheries managers to consider a number of management alternatives. Catch and release, a widely used management tool in freshwater systems, is becoming more accepted in marine recreational fisheries (Muoneke and Childress 1994). Clearly, a critical factor in determining the success of size-related management strategies (e.g., slot limits) is postcapture survival. Despite the rapid integration of catch and release into many marine fish management programs, the data available to predict the success of such regulations are often limited (Matlock 2002).

The spotted seatrout Cynoscion nebulosus is one of the most sought-after recreational fishes landed in the southeastern USA. In the Gulf of Mexico, approximately 3.3 million anglers spent 23 million days fishing in 2003 and the most commonly captured species was the spotted seatrout (Van Voorhees and Pritchard 2004). Texas has an abundant spotted seatrout population: 1,000,000 individuals are harvested annually (Green and Campbell 2005). A long-term monitoring program (1982-2000) conducted by the

\footnotetext{
* Corresponding author: greg.stunz@tamucc.edu
}

Received October 25, 2005; accepted March 17, 2006 Published online November 6, 2006
Texas Parks and Wildlife Department (TPWD) suggests that the abundance and spawning biomass of spotted seatrout are at an all-time high (MartinezAndrade et al. 2005). Despite the apparent health of the spotted seatrout population, managers are concerned over decreasing availability of spotted seatrout larger than $635 \mathrm{~mm}$ total length (TL).

Texas has regulated the spotted seatrout fishery since 1978 using lower length limits (Hegen et al. 1987). From 1990 to 2003, the minimum size limit was 381 mm TL (Blanchet et al. 2001). In response to recent declines in the availability of trophy-size spotted seatrout ( $>635 \mathrm{~mm}$ or 25 in TL), the TPWD instated a somewhat controversial slot limit regulation. The lower size limit of $381 \mathrm{~mm}$ TL was retained, but an upper slot of $635 \mathrm{~mm}$ TL was added. Anglers are currently allowed to retain only one trophy-size fish per person per day. Controversy surrounding this regulation has arisen from anecdotal information supplied by recreational anglers, indicating that spotted seatrout exceeding the upper limit did not survive after release.

There have been few studies on catch-and-release mortality of inshore recreational fisheries (see review by Muoneke and Childress 1994), and the literature is inconclusive about the spotted seatrout mortality (0$70 \%$ ) elicited by this management method (Murphy et al. 1995; Duffy 2002). The new spotted seatrout 
regulations in Texas are based on studies that have reported widely ranging catch-and-release mortality in this species. For example, in Texas, studies reported mortalities ranging from $7 \%$ to $56 \%$ (Matlock and Dailey 1981; Hegen et al. 1987; Matlock et al. 1993). These studies examined fish of small size-classes; nevertheless, they provide the only data on mortality of spotted seatrout from catch and release.

Given the importance of the spotted seatrout fishery, the effects of catch-and-release mortality require further examination. The objectives of this study were to assess mortality of spotted seatrout that are hookand-line captured and released in Texas waters. Specifically, short-term mortality was assessed as a function of bait type, hook type, angler skill level, and fish size in replicate field enclosures; long-term mortality $(30 \mathrm{~d})$ was examined by holding fish in a laboratory facility.

\section{Methods}

This study was conducted in two Texas estuaries, Aransas and Corpus Christi bays, located in the western Gulf of Mexico. Spotted seatrout were collected from these bays during July-September 2003. We chose this period because it coincides with the warmest water temperatures, lowest dissolved oxygen levels, highest salinities, and presumably, the highest catch-and-release mortality rates. Spotted seatrout were captured by hook and line, simulating angling methods common to this fishery.

Volunteer anglers with a range of skill levels were recruited; however, beginner or novice anglers (defined below) were included only in the angler skill level trials. Collections were made while wadefishing by means of conventional casting tackle (medium action) with line of 5.4-7.2-kg test (12-16-lb test); terminal tackle varied depending on the experimental trial. All fish were landed by hand-gripping the fish dorsally; hooks were removed by hand or with pliers, and fish were placed in floating mesh baskets $(45-\mathrm{cm}$ diameter $\times 65-\mathrm{cm}$ length). Hooking location and general handling were noted but not included in the analysis; these were treated as factors of the experimental treatment. Fish were held in the mesh baskets for 15$30 \mathrm{~min}$ at ambient water conditions, measured for TL $(\mathrm{mm})$, and transferred to temporary insulated holding boxes (143-L cooler; Igloo, Katy, Texas) containing oxygenated bay water. The water quality of the holding boxes was monitored to approximate the ambient water conditions (salinity, temperature, and dissolved oxygen) at the collection site. Five fish were held in each temporary holding box; our goal was to capture 20 fish/ trip. Fish were held no longer than $4 \mathrm{~h}$ in these temporary holding boxes before transfer to experimental field holding enclosures.

For short-term trials $(72 \mathrm{~h})$, fish were transferred from temporary holding boxes to replicated experimental mesh field enclosures. Frames for five replicate holding enclosures $(2.4 \times 1.2 \times 1.2 \mathrm{~m}$ [length $\times$ weight $\times$ height]) consisted of a 19-mm-thick, polyvinylchloride (PVC) pipe frame covered with 6.4-mm, extruded black-plastic mesh attached with plastic cable ties. Four enclosures were used for experimental trials, and one was used for a control. The enclosures rested on the bay bottom and were secured in a shaded area beneath a dock. Depending on the tide levels, the water depth was about $1.5 \mathrm{~m}$ and the enclosures were usually totally submerged. Five spotted seatrout were stocked in each enclosure. On rare occasions, a fish would escape during transfer. Also, when not enough fish were captured to complete a replicate, we used only four fish. If a fish died during capture or transport process, only the remaining fish were used for that replicate, and mortality was calculated based on the original number of fish. Salinity $(\%)$, temperature $\left({ }^{\circ} \mathrm{C}\right)$, and dissolved oxygen $(\mathrm{mg} / \mathrm{L})$ were measured twice daily to assess environmental conditions. Fish were held in the field enclosures without food for $72 \mathrm{~h}$. After the holding period, fish were recovered and percent mortality was calculated. This collection process was repeated until we had 10 replicates (50 fish) for each experimental treatment.

One field enclosure was designated as a control. For each experimental trial, a group of five fish was used to assess the effect of caging on mortality. Control fish were captured at night in an area adjacent to the experimental holding facility. Spotted seatrout were attracted by use of submersible green lights, where they were easily captured by hook and line with small, plastic swimming baits. Although some handling was necessary to capture control fish, special care was taken to minimize stress. Immediately upon hooking, fish were not fought but were led through the water to the control field enclosure. Fish were gently placed in the enclosure, and the hooks were removed with minimal or no handling. Control fish were used for multiple experimental trials but were not held for longer than $7 \mathrm{~d}$.

We assessed the impact of angler skill level on catch-and-release mortality of spotted seatrout by identifying three groups of anglers: beginner, intermediate, and expert. Beginners were defined as novice anglers that had never fished before. Intermediate anglers were those who fished several times per month, routinely captured fish, and were skilled in use of their gear and in handling fish. Expert anglers were defined as those who fished many times per week; such anglers were often fishing guides or active tournament anglers. 


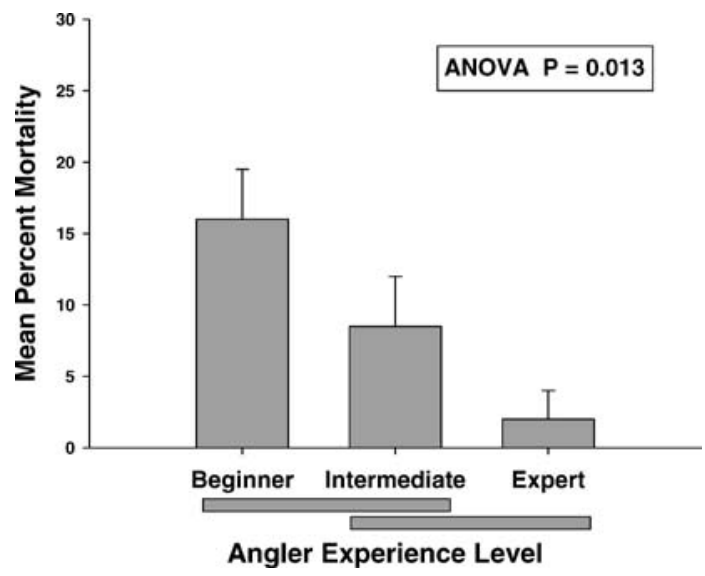

FIGURE 1.-Mean (SE) percent catch-and-release mortality of spotted seatrout captured by anglers of differing skill levels (beginner, intermediate, and expert). The $P$-value is from ANOVA ( $N=10$ replicates/treatment). Horizontal lines below the bars indicate results of Tukey's post hoc comparisons; bars sharing the same line are not statistically different $(\alpha=0.05)$.

Anglers were given no special handling instructions other than general gear operation and casting instruction for beginner anglers. Fifty fish per treatment level were captured by use of soft plastic, swimming-type lures with 1.8 -g jig heads and were stocked into 10 replicate experimental enclosures (5 fish/replicate) as described above.

To assess the effect of bait type on catch-and-release mortality of spotted seatrout, we captured fish on three common bait types used in recreational fishery: softplastic, swimming baits; live penaeid shrimp; and floating (topwater) plugs. The swimming baits used were the same as those used for skill-level trials. We used live penaeid shrimp hooked through the carapace with a treble hook (size 4) suspended beneath a float ("popping cork"). We used large, floating topwater plugs with three size- 2 treble hooks. Fifty fish were captured for each lure treatment level and were stocked into 10 replicate experimental enclosures (5 fish/ replicate) as described above.

We also assessed catch-and-release mortality for spotted seatrout captured with the three hook types most commonly used in the recreational fishery: offsetshank Kahle (size 3/0), straight-shank "J-shaped" (1.8g jig heads), and treble (size 4) hooks. Live penaeid shrimp were hooked through the carapace and suspended beneath a float for the Kahle- and treblehook treatments. Because straight-shank hooks are not typically used in the live-bait fishery, we used this hook type with the more common soft-plastic, swimming baits. We captured 50 fish each for Jshaped-hook and treble-hook treatment levels and 25 fish for the Kahle-hook treatment. Five fish per replicate were stocked into experimental enclosures.

To examine long-term mortality over $30 \mathrm{~d}$, we captured 27 spotted seatrout by using soft-plastic, swimming baits and topwater surface plugs as described above. These fish were handled in the field as previously described and were transported to the TPWD/Coastal Conservation Association Marine Development Center in Flour Bluff, Texas. The fish were measured (mm TL) and then stocked into an 11,300-L holding tank, where they were held for $30 \mathrm{~d}$. The fish were checked daily for mortalities and were fed to satiation with live penaeid shrimp and pinfish Lagodon rhomboides. Water temperature was maintained between $28^{\circ} \mathrm{C}$ and $29^{\circ} \mathrm{C}$, salinity was held at $37 \%$, and dissolved oxygen was maintained between 5 and $6 \mathrm{mg} / \mathrm{L}$.

\section{Statistical analysis.}

We used analysis of variance (ANOVA; $\alpha=0.05$ ) to assess angler skill level, bait, and hook-type trials. Mean percent mortality was calculated from each replicate enclosure and was arcsine transformed to convert a binomial distribution to a normal distribution (Zar 1996). Significant differences in ANOVA were further examined by use of Tukey's test for differences among treatment means $(\alpha=0.05)$. Simple linear regression $(\alpha=0.05)$ was used to examine relationships between mortality and fish size by examining shortterm mortality data from individuals across all trials and replicates. Spotted seatrout were assigned to 15 different size-cohorts from 388 total fish. At least five fish were represented in each cohort.

\section{Results}

To assess mortality of spotted seatrout associated with catch-and-release fishing practices, we captured 448 fish during July-September 2003. The mean fish size captured was $349 \mathrm{~mm}$ TL ( $\mathrm{SE}=4.4$; range $=230$ $740 \mathrm{~mm}$ TL). Fish were held in field enclosures (short term) or in laboratory facilities (long term). The combined overall mortality was relatively low (mean $=11.1 \% ; \mathrm{SE}=1.82 \%$ ). We observed no caging effect: survival was $100 \%$ for all spotted seatrout in our control treatments.

We found that angler skill level had a significant effect on spotted seatrout mortality $(P=0.013 ; F=$ 5.092; df $=2,27 ; N=10$; Figure 1). The higher mortality was associated more with beginner anglers than expert anglers. Our field observations suggest that novice anglers typically had more difficulty detecting the fish bite, which resulted in more frequent deep hooking of the fish and required more handling time. However, fish mortality was still relatively low (18\%), even for beginner anglers. 


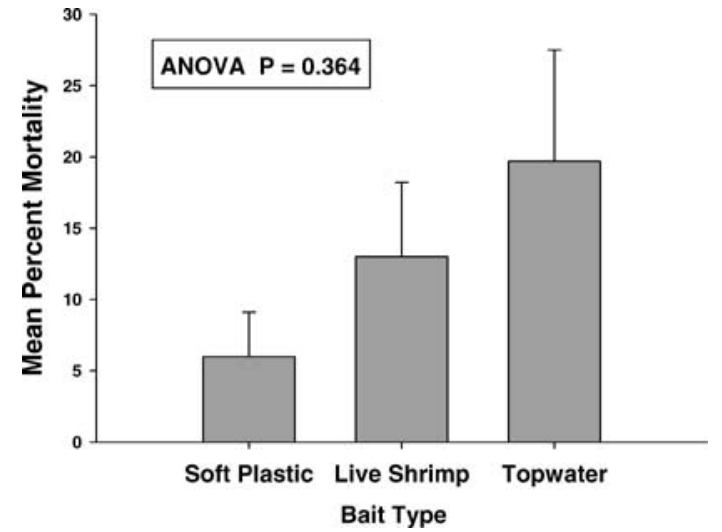

Figure 2.-Mean (SE) percent catch-and-release mortality of spotted seatrout captured by use of different bait types (soft plastic, live shrimp, and surface topwater plugs). The $P$-value is from ANOVA $(N=10$ replicates/treatment.

In our examination of three bait types common to the recreational fishery, results suggested that bait type had no significant effect on catch-and-release mortality $(P$ $=0.364 ; F=1.445 ; \mathrm{df}=2,27 ; N=10 ; 1-\beta=0.111$; Figure 2). Variability within treatment levels was relatively high, particularly for live-shrimp and surface baits. Mortality appeared to be a function of hooking location, and certain bait types were more prone to deep hooking (e.g., live shrimp) or caused mortal external wounds from large treble hooks (topwater surface baits). Hooking location appeared to be more important than bait type in determining mortality.

We found that hook type had no significant effect on spotted seatrout mortality $(P=0.691 ; F=0.375$; df $=$ 2,$22 ; N=10 ; 1-\beta=0.049$; Figure 3 ). For all hook types, mean mortality was less than $10 \%$. Some variability was noted for treble hooks, and as in the bait-type trials mortality was a function of hooking location. For example, treble hooks were more prone to hooking deeply or in the gills. Fish hooked in this manner typically did not survive, but the trends were not significant.

To examine size-related catch-and-release mortality, we used simple linear regression for 388 fish. For groups of more than five fish, we assigned the fish to 24.5-mm size-cohorts ranging from 229 to $660 \mathrm{~mm}$ TL and determined percent mortality for each size-cohort (Figure 4). We captured only seven fish larger than 635 $\mathrm{mm}$ (the new upper slot limit; these fish were therefore grouped together into one size-cohort. We did not find a significant relationship between fish size and mortality $(P=0.904 ; F=0.0153 ; \mathrm{df}=1,14 ; N=$ $15 ; 1-\beta=0.034)$.

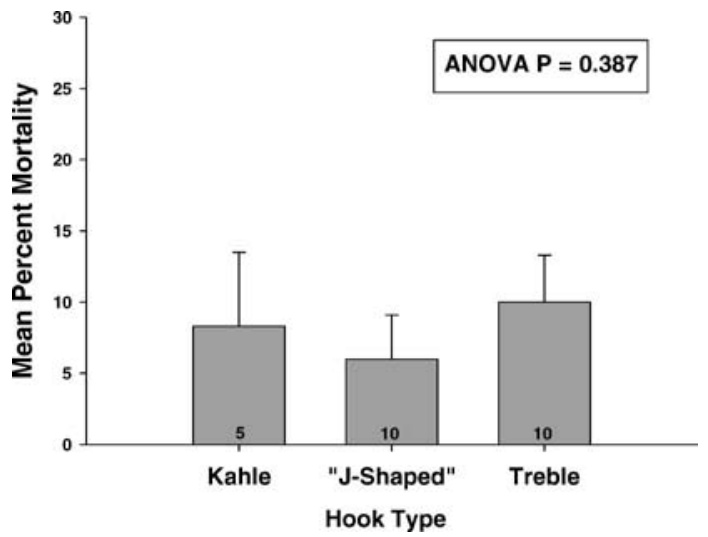

FIGURE 3.-Mean (SE) percent catch-and-release mortality of spotted seatrout captured with different hook types (offsetshank Kahle, straight-shank j-shaped, and treble hooks). The $P$-value is from ANOVA; the number of replicates per treatment is shown at the base of each bar.

To examine long-term mortality, we captured 27 spotted seatrout with a mean size of $355 \mathrm{~mm}$ TL ( $\mathrm{SE}=$ 17.9) and stocked them into long-term holding tanks in a laboratory facility. During the first $48 \mathrm{~h}$, a mortality rate of $11.1 \%$ (three fish died) was observed. This mortality rate was typical of results for our other experimental trials. At the end of the 30-d period, $100 \%$ of the remaining 24 fish had survived.

\section{Discussion}

We investigated the mortality associated with catch and release in the spotted seatrout fishery in Texas. Specifically, we investigated short-term mortality of hook-and-line-captured spotted seatrout as a function of bait type, hook type, angler skill level, and fish size, and we also assessed long-term mortality. Overall, we observed relatively low mortality rates and high longterm survival of spotted seatrout.

In general, reported mortalities for spotted seatrout have been highly variable, ranging from $0 \%$ to $70 \%$ (Muoneke and Childress 1994). Overall mortality (11\%) for this study was consistent with or generally lower than estimates reported in other studies of spotted seatrout. Murphy et al. (1995) found 4.6\% mortality for spotted seatrout in Florida waters. Matlock and Dailey (1981) reported mortality of up to $56 \%$ for spotted seatrout in Texas; however, another Texas study (Hegen et al. 1987) reported 37\% mortality. The wide variation in mortality rate may be attributed to differences in study design, limited replication, few or no fish in larger size-classes, and variation in handling methods; the variation clearly points to the need for further study. 


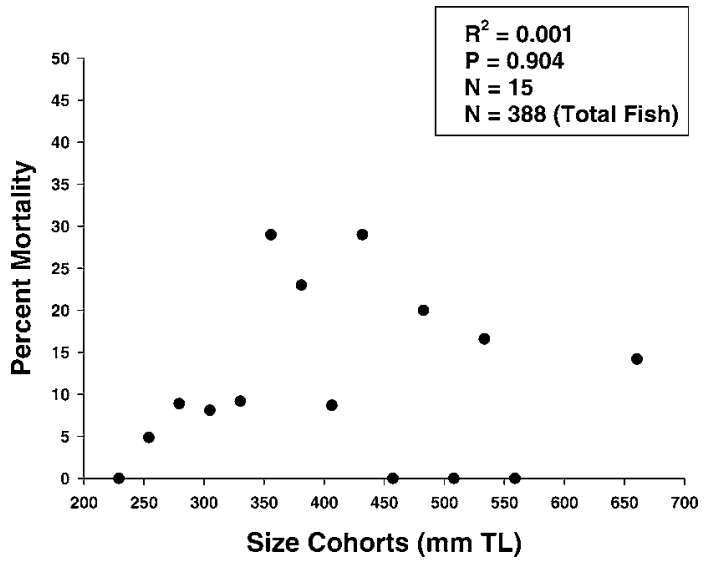

FIGURE 4.-Relationship between spotted seatrout size ( $\mathrm{mm}$ TL) and percent catch-and-release mortality. The $P$-value is from simple linear regression. Fish $(n=388)$ were assigned to 15 different size-cohorts (at least 5 fish/cohort were present).

These results suggest that angler skill level has the most significant effect on the postrelease survival of spotted seatrout; survival increased as angling skill level increased. These results are not surprising given that beginning anglers are generally not as skilled at detecting the fish bite, resulting in more deeply hooked fish with greater mortality. Hooking location was not a factor in our analyses, and it was treated as a component of the experimental treatment; however, we did observe a higher number of deeply hooked fish with novice anglers, and these fish typically did not survive. Additionally, we observed less handling as angling skill level increased. Despite these significant findings, even with beginning anglers the average mortality was only $18 \%$. Accordingly, novice anglers were not included in other trials so as to facilitate the detection of treatment effects.

We did not observe an effect of bait or hook type on catch-and-release mortality. As in skill level trials, hooking locations were treated as factors of the bait or hook type and were not considered as independent measurements. Previous studies have reported little effect of bait and hook types on mortality in this species. Matlock et al. (1993) reported no differences among bait and hook types for spotted seatrout in the Texas recreational fishery. In Alabama, Duffy (2002) reported no differences in mortality associated with treble hooks versus single hooks. Although no significant mortality differences were observed between topwater surface baits and other bait types, we did find substantial variation within this experimental treatment as well as low statistical power. The surface baits were fitted with large treble hooks, and depending on the hooking location these baits often inflicted hook wounds in the abdomen and gill areas. These hooking injuries often caused large (several centimeters long) wounds that penetrated the body cavity and occasionally damaged the gills, leading to excessive bleeding. The differences in hooking location were probably the reason for the large variability within this treatment.

Our results suggest that fish size has no significant effect on catch-and-release mortality of spotted seatrout. We found no significant relationship between fish length and percent mortality. Previous studies examining spotted seatrout catch-and-release mortality have not considered the relationship between fish length and mortality (Matlock and Dailey 1981; Hegen et al. 1987; Matlock et al. 1993; Murphy et al. 1995; Duffy 2002), and this relationship can have important implications under different management scenarios (Muoneke and Childress 1994). The limited nature of investigations on size-related mortality is probably related to the difficulty of catching sufficient numbers of large trout to carry out replicated studies. This was a factor in our study, as we only captured seven fish larger than $635 \mathrm{~mm}$ TL and thus grouped these fish into one cohort. Size-related catch-and-release information is important for this species, given the new upper-limit regulations in Texas. Previous anecdotal evidence suggested high catch-and-release mortality associated with large individuals of this species; however, our results show no effect of size-related mortality.

Typically, catch-and-release studies have been limited in scope, and very few have considered longterm effects beyond 48-72 h (Matlock and Dailey 1981; Hegen et al. 1987; Matlock et al. 1993; Murphy et al. 1995; Duffy 2002). This delayed mortality is often unknown (Schramm et al. 1987; Muoneke and Childress 1994; Neal and Lopez-Clayton 2001). We are not aware of any studies examining long-term mortality for spotted seatrout. For the relatively few fish that died in our experimental trials, most mortality occurred within the initial $48 \mathrm{~h}$; fish surviving beyond this time period in our long-term study showed $100 \%$ survival. While the fish were in captivity, we visually observed signs of capture such as hand prints in the mucous layer along the nape and shoulder regions and wounds around hooking locations near the mouth. As the fish began to actively feed (within $\sim 7 \mathrm{~d}$ ), these wounds readily healed and no long-term mortality was observed.

This study was conducted during the warmest summer months coinciding with the maximum potential for stress-related catch-and-release mortality; however, other seasonal effects may have been involved (e.g., high temperature, high salinity, and low dissolved oxygen level), and the effects of these 
variables need further investigation. Although the primary factor influencing mortality was angler skill level, an overriding factor in all experimental trials independent of treatment level was anatomical hooking location. Hooking location was treated as a component of the experimental treatment level and not as a factor in our analyses. The location of hook-related injuries may be an important factor in determining catch-andrelease mortality for spotted seatrout. Future investigations should examine the effects of handling stress, seasonal factors, and anatomical hooking locations on spotted seatrout mortality. The fish in our experimental trials underwent considerable handling, yet we observed relatively low mortality $(\sim 11 \%$ overall $)$. We suggest that fish released at the site of capture may experience even higher survival rates than that seen in this study. These data lead us to conclude that management options involving the release of spotted seatrout, including release of fish larger than $635 \mathrm{~mm}$ $\mathrm{TL}$, are viable tools.

\section{Acknowledgments}

Funding for this study was provided by the Coastal Conservation Association and Texas A\&M University-Corpus Christi (TAMUCC). This research was conducted through the Fishery Ecology Laboratory at TAMUCC. The help from everyone in the laboratory was essential for the successful completion of the project. Special thanks to Amanda Bushon, Ramiro Cervantes, Paul Gonzales, Jason James, and Megan Reese for contributions, input, assistance in the field and laboratory, and manuscript preparation and review. We gratefully acknowledge TPWD for providing the laboratory facilities used in long-term mortality trials.

\section{References}

Blanchet, H., M. Van Hoose, L. McEachron, B. Muller, J. Warren, J. Gill, T. Waldrop, J. Waller, C. Adams, R. B. Ditton, D. Shively, and S. VanderKooy. 2001. The spotted seatrout fishery of the Gulf of Mexico, United States: a regional management plan. Gulf States Marine Fisheries Commission, Publication Number 87, Ocean Springs, Mississippi.

Duffy, J. 2002. Catch-and-release mortality studies of spotted seatrout and red drum in coastal Alabama. Pages 110 113 in J. A. Lucy and A. L. Studholme, editors. Catch and release in marine recreational fisheries. American Fisheries Society, Bethesda, Maryland.

Green, L. M., and R. P. Campbell. 2005. Trends in finfish landings of sport-boat anglers in Texas marine waters May 1974-May 2003. Texas Parks and Wildlife Department, Management Data Series 234, Austin.

Hegen, H. E., G. E. Saul, and G. C. Matlock. 1987. Survival of handled and tagged spotted seatrout held in wood and wire cages. Texas Parks and Wildlife Department, Management Data Series 61, Austin.

Martinez-Andrade, F., P. Campbell, and B. Fuls. 2005. Trends in relative abundance and size of selected finfishes and shellfishes along the Texas coast: November 1975December 2003. Texas Parks and Wildlife Department, Management Data Series 232, Austin.

Matlock, G. C. 2002. Why does marine fisheries management now require releasing caught fish? Pages $15-18$ in J. A. Lucy and A. L. Studholme, editors. Catch and release in marine recreational fisheries. American Fisheries Society, Bethesda, Maryland.

Matlock, G. C., and J. A. Dailey. 1981. Survival of hookcaught spotted seatrout held in cages. Texas Parks and Wildlife Department, Management Data Series 15, Austin.

Matlock, G. C., L. W. McEachron, J. A. Dailey, P. A. Unger, and P. Chai. 1993. Short-term hooking mortalities of red drums and spotted seatrout caught on single-barb and treble hooks. North American Journal of Fisheries Management 13:186-189.

Muoneke, M. I., and W. M. Childress. 1994. Hooking mortality: a review for recreational fisheries. Reviews in Fisheries Science 2:123-156.

Murphy, M. D., R. F. Heagey, V. H. Neugebauer, M. D. Gordon, and J. L. Hintz. 1995. Mortality of spotted seatrout released from gill-net or hook-and-line gear in Florida. North American Journal of Fisheries Management 15:748-753.

Neal, J. W., and D. Lopez-Clayton. 2001. Mortality of largemouth bass during catch- and-release tournaments in a Puerto Rico reservoir. North American Journal of Fisheries Management 21:834-842.

Schramm, H. L., Jr., P. J. Haydt, and K. M. Portier. 1987. Evaluation of prerelease, postrelease, and total mortality of largemouth bass caught during tournaments in two Florida lakes. North American Journal of Fisheries Management 7:394-402.

Van Voorhees, D. V., and E. S. Pritchard. 2004. Fisheries of the United States 2003: marine recreational fishery statistics survey. U.S. National Marine Fisheries Service, Silver Spring, Maryland.

Zar, J. H. 1996. Biostatistical analysis, 3rd edition. PrenticeHall, Englewood Cliffs, New Jersey. 